\title{
SISTEMA AGROINDUSTRIAL DA CANA: CENÁRIOS E AGENDA ESTRATÉGICA
}

\author{
Marcos Fava Neves \\ Marco Antonio Conejero ${ }^{\S}$
}

\begin{abstract}
RESUMO
O artigo apresenta números recentes do sistema agroindustrial da cana-de-açúcar no Brasil e tendências para o álcool, açúcar e energia. Utilizando a metodologia de análise macroambiental, traz as principais ameaças e oportunidades ao sistema, nas variáveis político-legais (institucionais), econômico-naturais, socioculturais e tecnológicas. Da mesma forma, por meio de uma análise interna, levanta os pontos fortes e fracos em cinco dimensões analíticas: produção, comunicação, logística, capacitação e coordenação. Finaliza, por intermédio do método de planejamento e gestão estratégica de sistemas produtivos (GESis), propondo uma agenda estratégica, com políticas públicas e privadas, para o crescimento contínuo e sustentável deste importante sistema produtivo da economia brasileira e mundial.
\end{abstract}

Palavras-chave: cana, açúcar, álcool, planejamento, agenda.

\begin{abstract}
The article presents data about the sugar cane agribusiness system (AGS) in Brazil, and trends for ethanol, sugar and bioenergy. Making use of the macro environmental (STEP) analysis, it's possible to know opportunities and threats to the whole system, in terms of politic-legal (institutional), economic-environmental, socio-cultural and technological variables. At the same time, through the internal analysis, it can be showed strength and weak points in terms of five analytical dimensions: production, communication, logistics, personal capabilities and coordination. To finish, through the productive system (chain) strategic planning method, it can be generated a strategic agenda, with public and private policies, for the sustainable growth of this important productive system in the Brazilian and global economy.
\end{abstract}

Key words: sugar cane, sugar, ethanol, planning, agenda.

JEL Classification: Q13, Q42, Q48.

$\S$ Professor Livre Docente da FEA/USP - Ribeirão Preto. Coordenador do PENSA e MARKESTRAT. E-mail: mfaneves@usp.br.

a Doutorando em Administração de Empresas pela FEA/USP. E-mail: marcoa@usp.br. Endereço para contato: Av. dos Bandeirantes, 3900 - Sala 64C. CEP 14040-900 - Ribeirão Preto - SP.

Recebido em setembro de 2007. Aceito para publicação em dezembro de 2007. 


\section{INTRODUÇÃo}

\subsection{Importância do setor e grandes números}

O Sistema Agroindustrial (SAG) da cana-de-açúcar é complexo: as usinas produtoras dependem de fornecedores de cana e de bens de capital. Os produtos, álcool, açúcar e energia, são distribuídos para distribuidores de combustíveis, distribuidores de energia elétrica, indústria de alimentos, atacado e varejo, e tradings exportadoras. Os subprodutos são destinados às indústrias, atacado e varejo, como indústrias de suco de laranja e de ração animal. Hoje, as usinas utilizam os resíduos, como vinhaça e vinhoto, como biofertilizantes.

O Brasil é o País que apresenta o maior crescimento na produção de cana. Em 2006, a quantidade produzida atingiu 420 milhões de toneladas; em 2007/2008, a estimativa é de 470 milhões. Em média, 60\% da cana colhida é destinada à produção de álcool (para todos os fins) e o restante para a produção de açúcar. Segundo dados da Unica (União da Agroindústria Canavieira), em 1975, a produtividade média brasileira era de 50 toneladas de cana por hectare, enquanto que, em 2005, a produtividade média foi de mais de 80 t/ha.

Segundo o IBGE, a produção de cana dividida por região do País revela que o Norte-Nordeste representa $15 \%$ da produção total do País e o Centro-Sul representa $85 \%$. Segundo a consultoria SCA, a produção do Centro-Sul continuará a se expandir e ser mais expressiva do que a produção do Norte-Nordeste. É previsto que a produção do País atinja mais de 450 milhões de toneladas em 2007/2008 e que, em 2010/2011, atinja 580 milhões de toneladas. Desde 1975, com a implantação do Proálcool, as áreas utilizadas na plantação de cana (em hectares) se expandiram e a previsão, até 2012, é que continuará a crescer, chegando a 7,8 milhões de ha. Em 2007/2008, a área ocupada com cana é de 6,2 milhões de ha.

O panorama geral brasileiro da economia da cana-de-açúcar, em 2006, é apresentado pelo Quadro 1, a seguir. No geral, a produção de álcool foi de 17,5 bilhões de litros e a de açúcar, 30 milhões de toneladas. Destas, 3,6 bilhões de litros de álcool (20\%) e 19 milhões de toneladas de açúcar (63\%) foram destinados ao mercado externo. 


\section{Quadro 1 - Panorama geral do setor sucroalcooleiro - 2006 - Brasil}

\begin{tabular}{|c|c|}
\hline Faturamento total: & US $\$ 20.5$ bilhões \\
\hline Geração de renda: & $\begin{array}{l}\text { PIB Brasil: US\$ } 900 \text { bilhões (100\%) } \\
\text { PIB Agronegócios: US\$ } 250 \text { bilhões (28\%) (100\%) } \\
\text { PIB Cana: US\$ } 68 \text { bilhões }(7,5 \%)(27 \%)\end{array}$ \\
\hline Geração de empregos: & 4 milhões de empregos diretos e indiretos \\
\hline Fornecedores: & 72.000 produtores independentes \\
\hline Área cultivada: & 6 milhões de hectares ( $0,7 \%$ área total) \\
\hline Insumos: & 50 mil fornecedores de insumos agrícolas (vendas de US $\$ 4$ bilhões/ano) \\
\hline Moagem: & 420 milhões de toneladas de cana \\
\hline \multirow[t]{2}{*}{ Produção: } & 30 milhões de toneladas de açúcar \\
\hline & 17,5 bilhões de litros de etanol \\
\hline \multirow[t]{3}{*}{ Exportações: } & Mais de US\$ 8,5 bilhões \\
\hline & 19 milhões de toneladas de açúcar (US\$ 7 bilhões) \\
\hline & 3,6 bilhões litros de etanol (US\$ 1,5 bilhões) \\
\hline Impostos: & US $\$ 6$ bilhões em impostos \\
\hline Investimentos: & US\$ 2.5 bilhões/ano \\
\hline Agentes: & 414 usinas de açúcar e álcool e destilarias (em operação + projetos) \\
\hline
\end{tabular}

Fonte: MAPA, SECEX, Única, Jornal ProCana.

\section{O negócio açúcar}

De uma maneira geral, o consumo de açúcar é influenciado pelo preço do açúcar e de adoçantes alternativos, a disponibilidade de estoques de açúcar, a preferência dos consumidores, os avanços tecnológicos e as políticas governamentais. No entanto, a renda per capita e o crescimento da população são os dois fatores mais importantes, sendo que o último explica $85 \%$ do crescimento do consumo (F.O. Litch's).

Segundo a USDA (Departamento de agricultura dos EUA), a produção mundial de açúcar, em toneladas, entre 2002 e 2007, cresceu a uma taxa média de 1,12\% a.a. Os principais países produtores de açúcar são Brasil, Estados Unidos, Índia, Tailândia e China. A produção do Brasil equivale a $19 \%$ de toda produção mundial, ou seja, 30,8 milhões de toneladas; a produção da Índia, segunda maior do mundo (16\%), é de 25,1 milhões de toneladas. Em terceiro lugar, a produção de açúcar dos Estados Unidos, representando $10 \%$ de toda produção mundial, é de 16,1 milhões de toneladas.

Em relação ao comportamento do consumo mundial, entre 2002 e 2006, o crescimento foi de 1,28\% ao ano em média. Em 2006/2007, o consumo atingiu 146 milhões de toneladas. Segundo a F.O. Licht's, em 2014, o consumo mundial de açúcar deve chegar à casa dos 180 milhões de toneladas.

Entre 2001 e 2006, a produção brasileira de açúcar cresceu em média 8,61\% a.a. O IBGE revela que os três Estados produtores de açúcar no Brasil, em 2005/2006, que mais participaram na produção nacional são: São Paulo, com participação de 66\%; Alagoas, com 8,15\%, e Minas Gerais, com 6,74\%. Conforme os dados do MAPA e SECEX, de 30 milhões de toneladas produzidas na safra 2006/2007, o Brasil consumiu um pouco mais de 10 milhões. Para os próximos anos, é previsto 
que a exportação continue a representar mais de $60 \%$ do destino da produção brasileira de açúcar, que também tende a crescer.

\section{O negócio álcool}

Segundo a F.O.Licht's, a produção mundial de etanol cresceu em média 11,36\% a.a., entre 2002 e 2006. Os principais países produtores são Estados Unidos e Brasil, que, juntos, responderam por 3/4 da produção mundial. Em 2006, os Estados Unidos produziram 18,5 bilhões de litros e o Brasil produziu 17,5 bilhões de litros. A China foi o terceiro maior produtor com 3,8 bilhões de litros. O mercado americano de etanol foi o que mais cresceu nos últimos anos, em função da substituição do Metil Tércio Butil Éter (MTBE) pelo etanol como oxigenador da gasolina em vários Estados.

No Brasil, o álcool hidratado foi o mais produzido durante todo o período de 1982 e 2000. A partir daquele ano, o álcool anidro foi mais produzido do que o hidratado. No entanto, entre 2005/2006, a produção de álcool hidratado voltou a ser levemente superior que a produção do álcool anidro, devido ao crescimento dos veículos flex. Esta inovação tecnológica trouxe interessantes novidades, e com grande aceitação por parte dos consumidores para se aproveitar das diferenças de preços. (Ferreira et al., 2007).

Dos 27 Estados brasileiros, praticamente 21 são importadores e somente 6 exportadores de etanol. Alguns Estados, como Paraná e Minas Gerais, são produtores e importadores. Segundo a Unica, em 2005/2006, os cinco maiores produtores foram responsáveis por 85\% da produção nacional de etanol, sendo eles: São Paulo, com participação de 62\%, Paraná (7\%), Minas Gerais (6\%), Mato Grosso (5\%) e Goiás (5\%).

Conforme estudo da ICONE (Instituto de Estudos do Comércio e Negociações Internacionais), a produção de etanol projetada para 2012 nos EUA é de 45,2 a 51,4 bilhões de litros, cerca de duas vezes e meia a produção atual. O Brasil projeta uma oferta de 35,4 bilhões de litros para o mesmo ano, dobrando a produção verificada em 2006, assim como ocorrerá na União Européia.

O mercado internacional vem se abrindo especialmente para o álcool anidro, dadas as políticas governamentais de adição de álcool na gasolina. Alguns países já aprovaram metas obrigatórias e outros já possuem uma política de autorização da adição. O Quadro 2, a seguir, mostra um resumo das políticas propostas por alguns países, as quais têm enorme impacto na produção brasileira. 
Quadro 2 - Sinais mundiais para demanda por etanol

\begin{tabular}{|c|c|c|c|c|}
\hline País/ Região & $\begin{array}{c}\text { Capacidade } \\
\text { Produção } \\
\text { (bilhões litros) }\end{array}$ & \% adição & $\begin{array}{c}\text { Demanda } \\
\text { potencial } \\
\text { (bilhões litros) }\end{array}$ & Observações \\
\hline EUA & 18,5 & $5 \%(2012)$ & 28,4 & $\begin{array}{l}\text { Alguns estados permitem adição de 10\% } \\
\text { Adição obrigatória de 17\% em } 2022 \text { em analise. }\end{array}$ \\
\hline Brasil & 17,4 & 20 a $25 \%$ & $\begin{array}{l}10 \text { (somente } \\
\text { com metas de } \\
\text { adição) }\end{array}$ & $\begin{array}{l}\text { Isenção de } R \$ 0,28 / \text { litro (CIDE) } \\
\text { Carros flex fuel representam uma frota de } 2 \text { milhões. }\end{array}$ \\
\hline EU & 3,1 & $\begin{array}{c}2 \%-5,75 \% \\
(2010)\end{array}$ & 9,3 & $\begin{array}{l}\text { Isenção fiscal nos estados membros; possibilidade de } \\
10 \% \text { em } 2020 \text {. }\end{array}$ \\
\hline Canadá & 0,2 & $5 \%(2010)$ & 2,1 & $\begin{array}{l}\text { A adição obrigatória pode chegar a } 10 \% \text { em alguns } \\
\text { Estados. }\end{array}$ \\
\hline China & 3,8 & $10 \%$ & 7 & $\begin{array}{l}\text { Vigora em } 5 \text { províncias, cerca de } 16 \% \text { de adição. Pode } \\
\text { chegar a } 15 \% \text { em } 2010 \text {. }\end{array}$ \\
\hline Japão & 0,1 & $3 \%^{1}$ & 1,8 & Adição permitida de até $20 \%$ a partir de 2030 . \\
\hline Índia & 2,0 & $10 \%$ & 1,1 & Adição obrigatória de $20 \%$ em analise. \\
\hline Tailândia & 0,4 & $10 \%^{1}$ & 1,5 & \\
\hline Austrália & 0,2 & $10 \%$ & 2,1 & \\
\hline Filipinas & & $5 \%{ }^{1}$ & 0,2 & \\
\hline Argentina & 0,2 & $5 \%(2010)^{1}$ & 0,2 & Adição obrigatória de 5\% em análise \\
\hline
\end{tabular}

Fontes: World Watch Institute (2006), F.O. Litcht's, EIA/DOE, European Commission, Copersucar, Renewable Fuels Association (RFA).

(1) Adição permitida.

Com relação à demanda futura de etanol, o NIPE/Unicamp realizou uma simulação de substituição de $10 \%$ de gasolina por etanol. Os resultados revelam a produção necessária de 152 bilhões de litros de etanol/ano para atender à demanda atual (2002) e uma produção necessária de 225 bilhões de etanol/ano para atender a uma demanda futura (2025).

Em termos de mercado internacional, o Brasil é o único exportador significativo de etanol, apesar de os EUA serem o maior produtor mundial com elevados subsídios a sua produção. Os maiores importadores de etanol são: EUA (2,7 bilhões de litros), Japão (502 milhões de litros), Alemanha (430 milhões) e Holanda (422), segundo a fonte IETHA.

Em 2006, a exportação brasileira de etanol foi maior para os Estados Unidos, que importou mais de 1,7 bilhões de litros de etanol brasileiro (MAPA). Isso ocorreu em função da elevação do preço do milho no mercado americano, fato que não deve se repetir na próxima safra.

As exportações brasileiras de etanol, até 2001, representavam um valor pequeno em relação à produção. Em 2006, as exportações totais atingiram 3,6 milhões de $\mathrm{m}^{3}$. A previsão é que as exportações e produção cresçam nos próximos anos, atingindo, respectivamente, 5 milhões de $\mathrm{m}^{3}$ e 26 milhões de $\mathrm{m}^{3}$, em 2010 (Consultoria SCA).

Em termos de mercado interno, em março de 2003, o carro bicombustível foi lançado. A sua importância ocorre por transferir ao consumidor o poder de decisão sobre qual combustível usar, independente da falta de produto ou aumento de preços. Nesse ano, sua participação sobre o total de veículos vendidos foi de 6,8\%. Em 2006, essa participação passou a ser de $86 \%$. Em unidades, 
em 2006, as vendas de carros flex no Brasil foram de aproximadamente 2 milhões de unidades. Em 2007, a previsão é que a venda de carros flex fuel aumente, e passe a ser maior do que 3 milhões de unidades (ANFAVEA).

De uma maneira geral, o preço na bomba do etanol é influenciado pelo preço do produtor, misturas exigidas por lei (álcool anidro na gasolina - 20\%), custo da logística de distribuição e carga tributária. No entanto, o que influencia efetivamente o consumo são os preços relativos dos diferentes tipos de combustíveis, o consumo por $\mathrm{Km}$ do veículo e a frota (lançamento dos veículos flex, proibição de veículos leves a diesel, etc.).

\section{O negócio energia}

Uma tonelada de cana gera cerca de $320 \mathrm{~kg}$ de bagaço, do quais $90 \%$ são usados na produção de energia. A importância da co-geração de energia utilizando o bagaço reside no fato de que ela coincide com o período de seca dos reservatórios das usinas hidrelétricas e, dessa forma, possui importante caráter complementar.

A capacidade de co-geração de energia com o bagaço, para produção de açúcar e álcool e exportação do excedente, é atualmente de $1650 \mathrm{MW}$ ou $2 \%$ da demanda nacional. No entanto, o aproveitamento de todo potencial energético do bagaço está longe do ideal, muito por conta do uso apenas de parte da produção de bagaço e do desperdício de energia com as tecnologias intermediárias e obsoletas apresentadas pelas termoelétricas das usinas. O potencial de co-geração de energia para 2012, com aproveitamento de $50 \%$ do bagaço, é de 9 mil MW ou $8 \%$ da demanda nacional projetada (ANEEL/ÚNICA).

\subsection{Preocupação de planejamento estratégico do SAG Cana}

Para que o Brasil assuma uma posição de importante fornecedor mundial de alimentos e bioenergia, é preciso desenvolver expertise na construção de sistemas agroindustriais que serão cada vez mais transnacionais e deverão ser sustentáveis. No entanto, há alguns desafios a serem vencidos: perseguir a estabilidade socioeconômica do País, continuar o crescimento em commodities agrícolas, capturar valor e promover o associativismo (coordenação vertical e horizontal) nos sistemas agroindustriais. E, nesse processo, o planejamento é indispensável para a compreensão dos sistemas produtivos, monitoramento do ambiente internacional e ajustamento de ofertas às mudanças em curso. A construção e elaboração de cenários e agenda estratégica para o sistema agroindustrial da cana é o foco deste artigo.

\section{OBJETIVO E PROCEDIMENTOS METODOLÓGICOS}

O objetivo central deste artigo é: a) realizar uma análise macroambiental (análise PEST) para o sistema agroindustrial (SAG) da cana no Brasil; b) vislumbrar, em cinco grandes áreas analíticas, seus pontos fortes e fracos; visando c) propor uma agenda estratégica para o setor para colaborar com discussões que vem sendo realizadas.

Os procedimentos metodológicos ficaram definidos como: 1) uma revisão do método GESIS (Planejamento e Gestão Estratégica de Sistemas Agroindustriais), proposto por Neves (2006), que se segue; 2) uma revisão bibliográfica específica sobre o sistema agroindustrial da cana (SAG 
Cana), conforme apresentado na introdução, e 3) entrevistas em profundidade com especialistas do setor, do governo e organizações multilaterais.

Com base na revisão da literatura e estudos realizados pelo PENSA (Centro de Conhecimento em Agronegócios da USP), Neves (2007) propõe, como contribuição metodológica, um processo de 12 etapas visando à implementação de gestão estratégica em sistemas produtivos. O Método GESis vem sendo utilizado para processos de planejamento e gestão estratégica para sistemas produtivos no Brasil. A Figura 1, a seguir, mostra as etapas que poderiam ser usadas para confecção de um plano estratégico para o SAG Cana nos próximos cinco ou dez anos. No Quadro 3, que se segue, cada uma das etapas será detalhada.

\section{Figura 1 - Resumo do Método GESis}

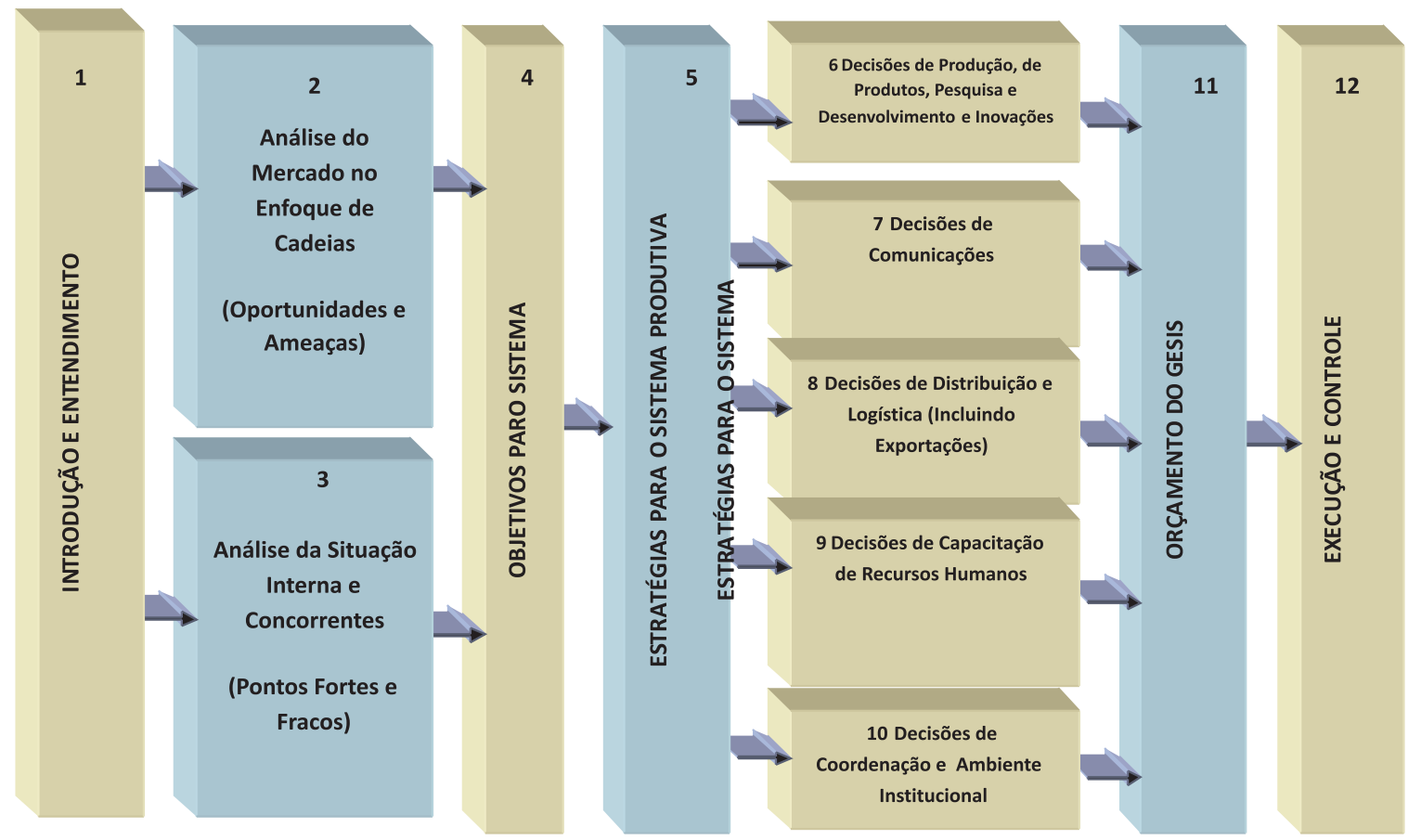

Fonte: Neves (2006). 
Quadro 3 - Planejamento e gestão estratégica para o sistema produtivo (método GESis) - seqüência detalhada dos passos propostos

\begin{tabular}{|c|c|}
\hline Etapa & 0 que deve ser feito \\
\hline \multicolumn{2}{|r|}{ Fase 01 - Introdutória } \\
\hline $\begin{array}{l}1 \text { - Introdução e } \\
\text { Entendimentos }\end{array}$ & $\begin{array}{l}\text { - Elaborar o histórico do sistema no mercado. } \\
\text { - Verificar se o sistema tem outros planos feitos e estudá-los. } \\
\text { - Verificar como é o método de planejamento do sistema sendo estudado. } \\
\text { - Verificar quais equipes estarão participando do processo. } \\
\text { - Buscar planos feitos para sistemas produtivos em outros países, para benchmark. } \\
\text { - Levantar, na equipe, uma pessoa que poderia ser um promotor do relacionamento com outros sistemas. } \\
\text { - Finalmente, deve-se verificar, em casos de sistemas com processos de planejamento já sofisticados, como } \\
\text { este modelo pode ajudar o modelo existente, e adaptar, gradualmente, o sistema a este. }\end{array}$ \\
\hline $\begin{array}{l}2 \text { - Análise do } \\
\text { Mercado no } \\
\text { Enfoque de } \\
\text { Cadeias }\end{array}$ & $\begin{array}{l}\text { - Levantar as ameaças e oportunidades advindas das chamadas variáveis incontroláveis (possíveis mudanças } \\
\text { no ambiente político/legal, econômico e natural, sociocultural e tecnológico) tanto no mercado nacional como } \\
\text { internacional. } \\
\text { - Entender as barreiras (tarifárias e não tarifárias) existentes e verificar ações coletivas para sua redução. } \\
\text { - Analisar o comportamento do consumidor final e intermediário (distribuidores) e seus processos de decisão } \\
\text { de compra. } \\
\text { - Analisar oportunidades para adequação ao meio ambiente, ao comércio justo, à sustentabilidade e aos } \\
\text { objetivos de desenvolvimento sustentável. } \\
\text { - Analisar oportunidades para adequação ao ambiente institucional trabalhista nacional e internacional. } \\
\text { - Montagem de um Sistema de Informações para que o sistema possa estar sempre informado e tomando } \\
\text { decisões com suporte e embasamento. } \\
\text { - Descrição dos principais concorrentes nacionais e internacionais. }\end{array}$ \\
\hline $\begin{array}{l}3 \text { - Análise da } \\
\text { Situação Interna e } \\
\text { Concorrentes }\end{array}$ & $\begin{array}{l}\text { - Levantar todos os pontos fortes e fracos do sistema. } \\
\text { - Mapeamento dos contratos e das formas de coordenação existentes } \\
\text { - Descrever as estruturas de governança existentes, com as características das transações. } \\
\text { - Fazer também esta análise em relação aos seus principais concorrentes. } \\
\text { - Análise da criação de valor, recursos e competências do sistema. } \\
\text { - Análise dos fatores críticos de sucesso do sistema. } \\
\text { - Selecionar, dentre os sistemas (que podem ou não ser concorrentes) quais e em que áreas serão benchmark } \\
\text { (fontes de boas idéias). }\end{array}$ \\
\hline $\begin{array}{l}\text { 4- Objetivos para } \\
\text { o Sistema }\end{array}$ & $\begin{array}{l}\text { - Principais objetivos devem ser definidos e quantificados visando ao crescimento sustentável e à solução dos } \\
\text { problemas colocados como pontos fracos. } \\
\text { - Propostas de Políticas: Estado, Organizações de Interesse Privado e Empresas. }\end{array}$ \\
\hline $\begin{array}{c}\text { 5- Estratégias } \\
\text { para Atingir } \\
\text { os Objetivos } \\
\text { Propostos }\end{array}$ & $\begin{array}{l}\text { - Listar as principais estratégias (ações) que serão usadas para atingir os objetivos propostos no item } 4 \text {. } \\
\text { - Fazer, aqui também, um grande resumo das ações que estão previstas na fase } 02 \text { (após o termino da redação } \\
\text { do plano, etapas } 6 \text { a 10). }\end{array}$ \\
\hline \multicolumn{2}{|c|}{$\begin{array}{c}\text { Fase } 02 \text { - Planos dos Vetores Estratégicos: Produção, Comunicação, Canais de Distribuição, Capacitação e Coordenação } \\
\text { (Adequação Institucional) }\end{array}$} \\
\hline $\begin{array}{c}\text { 6-Decisões de } \\
\text { Produção, de } \\
\text { Produtos, Pesquisa } \\
\text { e Desenvolvimento } \\
\text { e Inovações }\end{array}$ & $\begin{array}{l}\text { - Analisar os potenciais produtivos e capacidades de produção. } \\
\text { - Mapeamentos e planos para riscos em produção (sanitários e outros). } \\
\text { - Analisar produtos e linhas de produtos, bem como linhas de produtos complementares para decisões de } \\
\text { expansão. } \\
\text { - Levantar oportunidades de inovações no sistema produtivo, lançamento de novos produtos. } \\
\text { - Oportunidades de montagem de redes de inovação nacionais e internacionais. } \\
\text { - Parcerias com Universidades e com a área médica. } \\
\text { - Detalhar todos os serviços que estão sendo e que serão oferecidos. } \\
\text { - Tomar decisões com relação à construção de marcas conjuntas e selos de uso do sistema. } \\
\text { - Analisar e implementar os processos de certificação do sistema produtivo. } \\
\text { - Adequação dos produtos a normas e ao ambiente institucional. } \\
\text { - Sustentabilidade ambiental. } \\
\text { - Tomar decisões com relação às embalagens (rótulos, materiais, design). } \\
\text { - Orçar investimentos decorrentes desta etapa. }\end{array}$ \\
\hline
\end{tabular}




\begin{tabular}{|c|c|}
\hline $\begin{array}{l}7 \text { - Decisões de } \\
\text { Comunicações }\end{array}$ & $\begin{array}{l}\text { - Identificar o público-alvo que receberá a comunicação (mensagens do sistema produtivo). } \\
\text { - Desenvolver os objetivos desejados para esta comunicação (conhecimento de produto, lembrança de } \\
\text { produto, persuasão, entre outros). tentar atingir um posicionamento e mensagem única dos produtos } \\
\text { gerados pelo sistema. } \\
\text { - Definir o composto de comunicação que será utilizado. ou seja, definir o plano de propaganda, de relações } \\
\text { públicas e publicidade, promoção de vendas, entre outros. } \\
\text { - Fazer benchmark de filmes e materiais internacionais já usados por outros sistemas produtivos. } \\
\text { - Orçar as ações de comunicação e possivelmente determinar verba promocional anual envolvendo todos os } \\
\text { agentes da rede. } \\
\text { - Indicar como os resultados das comunicações serão medidos, para que o sistema aprenda cada vez mais a } \\
\text { usar as melhores ferramentas e veja o retorno dos investimentos. }\end{array}$ \\
\hline $\begin{array}{c}\text { 8-Decisões de } \\
\text { Distribuição e } \\
\text { Logística (Incluindo } \\
\text { Exportações) }\end{array}$ & $\begin{array}{l}\text { - Analisar os canais de distribuição dos produtos e buscar novos, definindo objetivos de distribuição, tais como: } \\
\text { presença em mercados, tipo e número de pontos de venda, serviços a serem oferecidos, informações de } \\
\text { mercado, promoção de produtos e incentivos. } \\
\text { - Analisar as possibilidades de captura de valor em canais de distribuição. } \\
\text { - Identificar possíveis desejos dos distribuidores internacionais e do consumidor para adequar os serviços por } \\
\text { Estados. } \\
\text { - Definir o modo de entrada nos mercados, se estas serão via franquias, via joint ventures ou outras formas } \\
\text { contratuais, ou até, mesmo, via integração vertical. } \\
\text { - Determinar orçamento anual para a distribuição. } \\
\text { - Verificar como ações na distribuição podem ser feitas em conjunto com outros sistemas. }\end{array}$ \\
\hline $\begin{array}{l}\text { 9- Decisões de } \\
\text { Capacitação do } \\
\text { Sistema Produtiva/ } \\
\text { Recursos Humanos }\end{array}$ & $\begin{array}{l}\text { - Treinamento em gestão para o sistema produtivo. } \\
\text { - Treinamento técnico da mão-de-obra, em controle de custos, para uso de tecnologias } \\
\text { - Treinamento em comercialização nacional e internacional. } \\
\text { - Transmissão e acesso às informações dos centros tecnológicos/pesquisa. } \\
\text { - Treinamento em produção de alimentos. } \\
\text { - Melhoria da assistência técnica nas propriedades. } \\
\text { - Outros }\end{array}$ \\
\hline $\begin{array}{c}\text { 10- Decisões } \\
\text { de Coordenação } \\
\text { e Adequação } \\
\text { ao Ambiente } \\
\text { Institucional }\end{array}$ & $\begin{array}{l}\text { - Projeto de redução da burocracia para obtenção de crédito. } \\
\text { - Projetos de melhoria da infra-estrutura básica. } \\
\text { - Projeto para homogeneização de tributos e incentivos. } \\
\text { - Projeto para aumento no consumo de programas governamentais. } \\
\text { - Programa para isolamento de áreas produtivas. } \\
\text { - Projeto para redução de tributos no sistema produtivo. } \\
\text { - Projeto para fortalecimento da atividade exportadora via APEX. } \\
\text { - Leis para incentivo ao uso das tecnologias (incentivo fiscal etc). } \\
\text { - Projeto para padronização dos produtos e nomes de produtos. } \\
\text { - Projetos para maior transparência nas legislações referentes a produtos e processos } \\
\text { - Propostas de sistemas de solução de conflitos. } \\
\text { - Propostas de coordenação. }\end{array}$ \\
\hline 11 - Orçamento & Todos os orçamentos dos projetos que trazem custos. \\
\hline \multicolumn{2}{|r|}{ Fase 03 - Implementação da Gestão Estratégica de Cadeias } \\
\hline $\begin{array}{l}12 \text { - Execução, } \\
\text { Controle, } \\
\text { Acompanhamento e } \\
\text { Correções }\end{array}$ & $\begin{array}{l}\text { Esta fase, que tem início após o término da elaboração do Plano, refere-se ao acompanhamento, às equipes } \\
\text { envolvidas e ações corretivas. O Plano deve ser um documento vivo, em constante discussão e atualização } \\
\text { no sistema. }\end{array}$ \\
\hline
\end{tabular}

Fonte: Neves (2007).

\section{RESUltados}

A etapa 2 do GESis refere-se à análise externa, ou seja, de oportunidades e ameaças. Nesta análise, usa-se a ferramenta "PEST ou STEP analysis", bastante consagrada na literatura. Ela con- 
sidera os principais fatores incontroláveis a um sistema produtivo, que variam, trazendo oportunidades e ameaças. Estes fatores são dos ambientes: político-legal; econômico-natural; sociocultural e tecnológico. (Neves, 2004; Campomar e Ikeda, 2006; Jain, 2000; Johnson e Scholes, 1988).

\subsection{Cenários: oportunidades e ameaças}

No ambiente político-legal: como principais oportunidades (que devem ser buscadas) e que podem beneficiar a cana, destaque para uma forte coordenação e reaproximação com os EUA, a redução tarifária, adição de etanol em outros países e a redução do ICMS dos Estados do Brasil, que distorcem o preço do álcool. Existem ameaças, tais como o levantamento de barreiras tarifárias (o que parece pouco provável), o perigo de barreiras "ambientais" e a lacuna de legislação para padronização visando à exportação (no mercado mundial). A proibição da queimada inviabilizará algumas áreas (maior ou menor impacto em usinas diferentes) e a própria legislação ambiental e trabalhista buscará cada vez mais a sustentabilidade.

No ambiente econômico e natural: destaque aqui para o incrível crescimento da frota flex no Brasil, a exportação da tecnologia e de usinas com o investimento no etanol e açúcar fora do Brasil, o crescimento do consumo de açúcar (produtos/alimentos que usam açúcar) no mundo, os preços firmes do petróleo, o investimento internacional no Brasil (queda do risco Brasil) e futuras quebras de produção em outros países. Também são oportunidades a aquisição de ativos e conseqüente concentração industrial e na produção (terras), a geração de divisas e contribuição para a estabilidade econômica, geração de tributos e de empregos nas usinas. Neste ambiente, existem ameaças que são o surgimento de novos concorrentes internacionais (Caribe, África), a falta de capacidade fabril para expansão (máquinas e equipamentos), uma forte redução do preço do petróleo (o que parece improvável), alguma doença ou praga na cana, uma variação climática trazendo redução da área disponível, a valorização do real diminuindo margens, o custo dos insumos (fertilizantes principalmente) e a concentração da venda de etanol a poucos grandes mercados (EUA) ou empresas (ex. Petrobras).

No ambiente sociocultural: são grandes oportunidades, pois tem-se um combustível verde e renovável, crescimento da preocupação das pessoas com relação ao meio ambiente e pressão internacional contra o avanço do biocombustível em áreas de produção de alimentos (beneficiando a cana). Ameaças também pairam e devem ser trabalhadas, como a imagem do emprego na colheita, a imagem de ocupação de terra (monocultura) e das queimadas.

Finalmente, no ambiente tecnológico: as oportunidades estão na frota de automóveis flex (ainda opção de automóveis maiores), na mecanização da colheita, uso da cana (etanol a partir da palha e bagaço), a modificação genética, o uso de satélites e agricultura de precisão, a pesquisa (novas variedades) e novas fontes de fertilizantes. Como ameaças, pode-se dizer que existem os produtos substitutos ao açúcar ou álcool, ganhos tecnológicos nos concorrentes da cana e tecnologias geradoras de energia mais competitivas que possam aparecer.

Entretanto, toda a produção terá que ser feita baseada no equilíbrio do tripé de sustentabilidade: ambiental (condições e características de produção), humana (respeito aos recursos humanos envolvidos) e econômica (lucros e distribuição de resultados). Existe uma visibilidade internacional muito grande no SAG Cana, e qualquer equívoco individual nestes três pilares será perigosamente generalizado pela mídia, no exterior, para toda a cana e, conseqüentemente, para o etanol produzido no Brasil. 


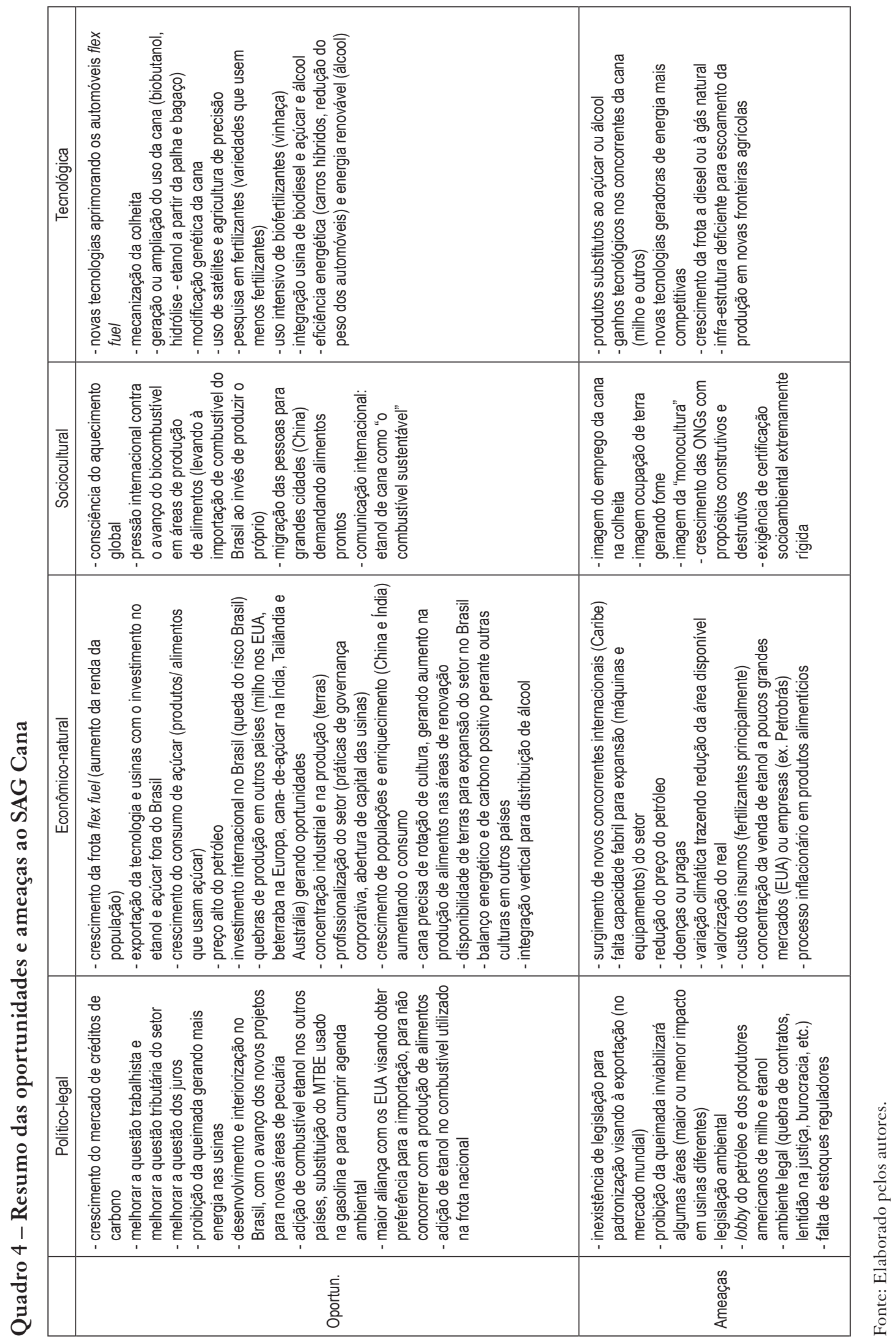




\subsection{Pontos fortes e fracos}

A seguir, tem-se uma análise interna ao setor, ou seja, por meio de uma radiografia, se chega a pontos fortes e pontos fracos. A idéia é que os pontos fortes possam ser potencializados, e os pontos fracos mereçam projetos visando a sua melhoria nos anos vindouros. As áreas, ou temas de análise dentro do método GESis, são divididas em cinco. Primeiramente, a questão da inovação, da pesquisa e da produção. Em seguida, a questão ligada à comunicação do sistema produtivo com seus clientes e consumidores. A terceira dimensão engloba as questões de distribuição e logística. A quarta dimensão analítica é a de capacitação, e a última, aspectos ligados à coordenação das cadeias produtivas e do ambiente institucional.

Quadro 5 - Resumo dos pontos fortes e fracos por área estratégica no SAG Cana

\begin{tabular}{|c|c|c|c|c|c|}
\hline & $\begin{array}{c}\text { Inovação/ pesquisa/ } \\
\text { produção }\end{array}$ & Comunicação & $\begin{array}{c}\text { Distribuição e } \\
\text { logística }\end{array}$ & Capacitação & $\begin{array}{c}\text { Coordenação e } \\
\text { institucional }\end{array}$ \\
\hline $\begin{array}{l}\text { Pontos } \\
\text { fortes }\end{array}$ & $\begin{array}{l}\text { - tecnologia flex fuel } \\
\text { - cana é imbatível } \\
\text { em custo (milho e } \\
\text { beterraba) } \\
\text { - capacidade da } \\
\text { indústria madura e } \\
\text { grande } \\
\text { - capacidade de áreas } \\
\text { novas } \\
\text { - não está no sistema de } \\
\text { alimentos } \\
\text { - variedades de cana }\end{array}$ & $\begin{array}{l}\text { - imagem de } \\
\text { combustível } \\
\text { verde, gerador de } \\
\text { emprego, ambiental, } \\
\text { exportação, } \\
\text { desenvolvimento } \\
\text { regional e } \\
\text { combustível } \\
\text { renovável } \\
\text { - publicidade "gratuita" }\end{array}$ & $\begin{array}{l}\text { - redes de postos } \\
\text { (32 mil no País) } \\
\text { - logística interna, } \\
\text { - presença da } \\
\text { Petrobras }\end{array}$ & $\begin{array}{l}\text { - base de capacitação } \\
\text { (universidade } \\
\text { e institutos de } \\
\text { pesquisa) é } \\
\text { excelente } \\
\text { - técnicos renomados } \\
\text { - profissionalização }\end{array}$ & $\begin{array}{l}\text { - Consecana } \\
\text { (contratos) } \\
\text { - diversidade de perfis } \\
\text { empreendedores } \\
\text { levando a ambiente } \\
\text { rico (geração de } \\
\text { idéias e discussão) }\end{array}$ \\
\hline $\begin{array}{l}\text { Pontos } \\
\text { fracos }\end{array}$ & $\begin{array}{l}\text { - pouco investimento em } \\
\text { pesquisa (foco foi dado } \\
\text { ao biodiesel) } \\
\text { - colheita manual e o } \\
\text { aspecto humano } \\
\text { - prática da queimada } \\
\text { - legislação trabalhista } \\
\text { - rentabilidade do elo } \\
\text { fornecedor }\end{array}$ & $\begin{array}{l}\text { - baixa capacidade de } \\
\text { antever problemas e } \\
\text { coordenar a reação } \\
\text { - problema de imagem } \\
\text { da mão-de-obra na } \\
\text { colheita, usineiro, } \\
\text { monocultura, } \\
\text { queimada e poluição, } \\
\text { - comunicação do setor } \\
\text { ainda incipiente }\end{array}$ & $\begin{array}{l}\text { - logística para a } \\
\text { exportação } \\
\text { - necessidade } \\
\text { de venda para } \\
\text { distribuidores } \\
\text { = "passeio do } \\
\text { álcool" } \\
\text { - custo da } \\
\text { distribuição: } \\
\text { custo Brasil }\end{array}$ & $\begin{array}{l}\text { - insuficiência de } \\
\text { pessoal ante o } \\
\text { crescimento } \\
\text { - poucos centros de } \\
\text { capacitação técnica } \\
\text { - pouca coordenação } \\
\text { nas organizações } \\
\text { que oferecem } \\
\text { capacitação } \\
\text { (institutos de } \\
\text { pesquisa e } \\
\text { universidades) }\end{array}$ & $\begin{array}{l}\text { - flutuação do preço } \\
\text { do álcool } \\
\text { - representação de } \\
\text { fornecedores no } \\
\text { aspecto quantitativo } \\
\text { - aparente falta } \\
\text { de planejamento } \\
\text { coordenado } \\
\text { - diversidade } \\
\text { dificultando a } \\
\text { coordenação } \\
\text { - baixa capacidade de } \\
\text { ação coletiva }\end{array}$ \\
\hline
\end{tabular}

Fonte: Elaborado pelos autores. 


\subsection{Agenda estratégica da cana}

Existem grandes projetos por área estratégica que podem assegurar a permanência das boas condições atuais para o setor sucroalcooleiro. Dentre os projetos a seguir, alguns são exclusivos da iniciativa privada, outros são públicos e outros, ainda, combinados.

\section{a) Decisões, ações e projetos relativos à produção, produtos, pesquisa, desenvolvimento e inovações:}

Diversas ações são recomendadas num plano para o setor nesta área de produção, pesquisa e desenvolvimento. As principais estão destacadas abaixo:

- Programas que visem ao crescimento vertical da produção de cana (mais produção na mesma área) devem ser estimulados.

- Mecanismos de incentivo a estoques estratégicos de álcool evitando flutuações de preços e escassez do produto. Os estoques reguladores podem melhorar a imagem do setor no Brasil e no mundo e fornecer segurança do abastecimento no mercado interno e externo.

- Atividades integradas de P\&D para o setor: estimular a formação de parcerias público-privadas (PPPs) e parques tecnológicos entre Embrapa, institutos agronômicos, centros de excelência nas universidades, empresas privadas, centros de tecnologia (como o CTC) e associações, com incentivos fiscais e aporte de recursos para o desenvolvimento de pesquisas conjuntas do setor. Deve-se ter uma plataforma tecnológica digital que mostre quais pesquisas estão sendo feitas, onde, quais pesquisadores; enfim, promovendo a integração.

- Estimular a integração e diversificação da agricultura voltada para a produção de alimentos e energia. Mediante aplicação de tecnologias, explorar a sinergia entre os dois tipos de plantio, desmistificando a visão de concorrência entre estes. A integração de usina de açúcar e álcool com planta de biodiesel permite adicionar um produto (biodiesel) ao mix de produtos das usinas.

- Criar um banco genético para cana-de-açúcar de domínio do setor, para atender à forte demanda por novas variedades de cana, resistentes a pragas e adaptadas a regiões mais áridas.

- Garantir o patenteamento internacional da tecnologia de produção do álcool brasileiro, para evitar a "livre importação" de tecnologia e capturar valor em cima das exportações de tecnologia e posteriormente, de royalties.

- Estimular a expansão da atividade canavieira principalmente em regiões onde existam pastagens degradadas ou subutilizadas. Este zoneamento deve também considerar que, para a economia dos municípios, é importante que outras culturas agrícolas permaneçam, viabilizando a coexistência com a cana e a diversificação econômica.

- Do lado da indústria de motores pequenos e grandes, precisa-se estudar a inovação por meio de motociletas movidas a álcool. Apesar de seu baixo consumo, contribuiriam muito para melhorar a qualidade do ar nos grandes centros urbanos. Também a adaptação de motores grandes a diesel para o álcool com novas tecnologias (já feito por uma empresa sueca e universidade), visando ao mercado dos caminhões dos fornecedores de cana e das usinas (e tratores), e de ônibus urbanos. Se as usinas pudessem abastecer sua frota de caminhões com o próprio álcool gerado, em regime de tributação privilegiada, muito do seu custo seria reduzido, podendo ser repassado ao preço final e mais ambientalmente correta seria esta cadeia produtiva, pois o grande volume de diesel consumido nas suas operações entra no balanço das emissões e na conta da sustentabilidade da cana de maneira muito negativa.

- Novos produtos a partir da alcoolquímica e sucroquímica, além de outros que já vem sendo desenvolvidos, como o plástico biodegradável de cana, e outros. 


\section{b) Decisões relativas à comunicação:}

Nesta área, são muitas as atividades que devem compor um plano ao setor. As principais estão destacadas a seguir:

- Divulgar mundialmente a imagem do Brasil como um fornecedor mundial de agroenergia e soluções ambientais (álcool combustível, biodiesel, créditos de carbono, tecnologias limpas, etc.). Para que o etanol de cana não seja confundido com etanol vindo de outras fontes concorrentes com alimentos, talvez fosse interessante rotulá-lo internacionalmente com outro nome, como, por exemplo, "cane-ethanol" ou "canethanol".

- Em convênio com prefeituras e empresas, ônibus urbanos poderiam ser testados a álcool (a UNICA vem fazendo isto), em escala muito maior. Na Suécia são 600, com custo apenas $3 \%$ superior. Estes ônibus, tal como os postos, seriam pintados e decorados com a cadeia produtiva, e neles a população teria conhecimento, informação, seja por meio de suas paredes, como por folders que seriam distribuídos, vídeos; afinal, seria um momento no qual todos gostariam de ler algo, rompendo a imagem que "da cana vem apenas o carvão". Mudando semanalmente de rotas, em 4 a 5 meses já teriam "falado" com toda a população usuária daquele município. Fora a melhoria nas condições do ar poluído das grandes cidades, seria um canal de comunicação permanente do setor com a comunidade.

- Está claro que a Petrobras terá condições de exportar gasolina pronta para consumo, já adicionada de anidro. É uma possibilidade clara para a Petrobras se tornar a primeira empresa petrolífera verde do planeta, entretanto ela precisa trabalhar mais rapidamente, pois tem um papel muito importante na imagem do álcool, que, juntamente com o biodiesel, também têm um papel muito importante na imagem da Petrobras.

- Trabalho conjunto das associações setoriais com a Apex (Agência de Promoção das Exportações) Brasil para promover a imagem do etanol como "combustível sustentável": reduz a dependência dos países em relação ao petróleo importado e escasso; estimula a adoção de tecnologias limpas (carros flex fuel, gasohol, produção local de forma sustentável, ampliação de redes de distribuição); garante um sistema de produção sustentável, com balanço energético elevado (reduz emissões de gases de efeito estufa); permite a co-geração de energia limpa (com uso do bagaço de cana); gera créditos de carbono; promove a inclusão de pequenos produtores com remuneração sustentável, e tem capacidade de estabelecer e honrar contratos de longo prazo.

- Criar lista de países prioritários para acordos comerciais (acordos de livre comércio e acordos de redução de tarifas) no caso do açúcar e do álcool.

c) Decisões relativas à distribuição e logística (incluindo exportações):

Entre as decisões ligadas à distribuição e logística, destacam-se:

- As usinas, por seu foco na atividade industrial, são muito conservadoras em avançar nos canais de distribuição. Usinas que estejam numa mesma região podem montar joint ventures e entrar no mercado de distribuição de álcool, com uma gestão independente, comprando distribuidoras hoje existentes ou montando novas, autorizadas a funcionar pelo governo.

- Ainda em canais de distribuição, as usinas, em formas organizacionais associativas, que podem ser franquias ou joint ventures, podem montar postos de combustível nas cidades. Estes postos não viriam para competir com as redes existentes (seriam poucos), mas seriam postos "conceito" (o nome da rede poderia ser verde ou "green”), e serviriam para duas funções básicas: a de estabelecer os preços varejistas do álcool (dificultando a ação de cartéis urbanos) e a de comunicação da imagem com o consumidor final, pois estes postos poderiam ser verdes, decorados com a cadeia da cana e com material de comunicação, plantio de árvores; enfim, uma 
rede "eco". Venderiam gasolina e diesel, mas em $80 \%$ das bombas, álcool. O conceito "loja de fábrica”.

- Melhoria da infra-estrutura de escoamento da produção de álcool. É necessário dar velocidade aos investimentos já anunciados de alcooldutos, bem como nas estruturas portuárias para a exportação de etanol.

- Agilizar as parcerias público-privadas (PPPs) que fortalecem um amplo programa de privatização de rodovias e outros aspectos de infra-estrutura visando não onerar o álcool que vem de regiões mais distantes e que hoje sofre com os problemas de custos de transporte no Brasil. Retomar a transferência de estradas, portos e áreas portuárias para o setor privado.

- Fortalecimento de alianças e joint ventures dos grupos exportadores de álcool, para compartilhar investimentos, reduzir riscos e ações conjuntas na logística de portos nacionais e internacionais, fretes e outros.

- Estimular a criação e ajudar no desenvolvimento de um contrato padrão para o etanol, que vem sendo desenvolvido pela IETHA (Associação Internacional para o Comércio do Etanol), entidade com quase 50 associados.

\section{d) Decisões relativas à capacitação de recursos humanos:}

Diversas ações são recomendadas num plano para o setor nesta área de recursos humanos e capacitação. Vale ressaltar que, com o crescimento do setor, existe hoje uma grande lacuna nesta área de pessoas.

As principais estão destacadas abaixo:

- Mapear os cursos técnicos e de graduação essenciais para o agronegócio da cana, bem como a sua distribuição espacial. Planejar, com o Ministério da Educação, a concessão de bolsas e incentivos à pesquisa.

- Implantar programas de capacitação para trabalhadores do agronegócio da cana, organizados pelas associações e sindicatos. Programas de reconversão de trabalhadores que perderam seus postos de trabalho com a mecanização.

- Promover reciclagem profissional dos funcionários públicos ligados aos agronegócios, para melhorar a atuação na gestão da qualidade dos alimentos, da saúde animal, da sustentabilidade e das certificações e rastreabilidade.

\section{e) Decisões relativas à coordenação e adequação ao ambiente institucional:}

Entre as principais ações na área de coordenação e ambiente institucional destacam-se:

- Primeiramente, os pontos principais que governos federais e estaduais poderiam se concentrar envolvem questões tributárias e de regulamentação. Urge que o álcool tenha a alíquota de ICMS reduzida para $12 \%$ em todos os Estados e ligeira redução de outros impostos federais. Agora que praticamente todos Estados terão produção, esta redução de arrecadação será compensada em parte pela produção, pelos investimentos que foram e estão sendo feitos, pelos salários gerados e outros impostos arrecadados. Fora os benefícios ambientais e de interiorização do desenvolvimento.

- Pode-se também estudar se a faixa de adição do anidro na gasolina poderia ser ampliada, dos atuais $20 \%$ a $25 \%$, para $18 \%$ a $28 \%$. Muitas pessoas com carros à gasolina já fazem esta adição maior por conta própria. Assim, em casos de grande produção, o uso de $28 \%$ poderia ajudar no consumo, e vice-versa.

- A partir de 1 de janeiro de 2010 apenas automóveis novos "flex fuel" poderiam ter autorização para emplacamento no Brasil. Apesar de o mercado sinalizar favoravelmente, observa-se que 
algumas montadoras ainda resistem, caso de coreanas, alemãs, japonesas e americanas, e o consumidor brasileiro não tem acesso a carros maiores com opção bicombustivel. Estima-se também que grande quantidade de veículos baratos entrará no Brasil, vindos da China e Índia, e não se pode correr o risco que venham apenas à gasolina. Até 2010, as montadoras teriam tempo suficiente para fazer esta simples adaptação e desovar estoques atuais. E poderiam, tal como as montadoras francesas, exportar estes carros e motores levando a tecnologia e consumo a outros mercados.

- Ainda na agenda governamental, é necessário pensar em alterações na forma de arrecadação dos impostos e permitir vendas diretas de álcool das usinas para os postos de gasolina. Com toda a inegável eficiência das distribuidoras de combustível, ainda, por menores que sejam as distâncias, existe passeio desnecessário do álcool e, em alguns casos, intermediação adicional. Esta liberalização contribuiria muito para um mercado mais competitivo. Vendas diretas.

- Constituir uma associação vertical aglutinadora, para o setor que pudesse representar todos os elos do setor. Promover o planejamento, em conjunto com o governo, por intermédio de associação vertical forte e representativa.

- À associação vertical cabe incentivar processos de terceirização da produção de cana por parte das usinas, incentivar o cooperativismo, o associativismo e o consórcio de produtores para aquisição de insumos e máquinas, arrendamento de terras e contratos de longo prazo com usinas.

- A associação vertical é responsável pela implantação de programas de marketing e promoção das exportações de álcool e açúcar (com presença nas principais feiras e exposições no mundo, em ações conjuntas com a Apex Brasil), com financiamento governamental e privado.

- Por intermédio da associação vertical, o governo pode monitorar a relação entre produtor e indústria, acompanhando a aplicação da forma de pagamento discutida e acordada entre todos os agentes do sistema Produtiva, sendo atualizado a cada safra agrícola. Neste sentido, o Consecana deve ser revisto, incorporando o bagaço de cana na equação, e se modernizando anualmente.

- Desenvolvimento de trabalho conjunto entre a associação vertical, a Associação Brasileira de Normas Técnicas e o Instituto Nacional de Metrologia, Normalização e Qualidade, para adequar o sistema agroindustrial da cana aos padrões de qualidade exigidos pelos países desenvolvidos, sobretudo na questão de sustentabilidade, com capacitação e adoção de certificados reconhecidos internacionalmente por parte dos agentes.

- Estimular a dormente capacidade que o setor tem de fornecer energia elétrica, por meio de marco regulatório claro e garantias de compra.

\section{CONSIDERAÇÕES FINAIS}

Muitos sistemas agroindustriais recebem admiração, mas a cana é especial, pela sua história, o benefício que traz para o Brasil, a liderança mundial e por ver o desenvolvimento das regiões produtoras. A cana ganhou uma legião de novos defensores e articulistas nos últimos anos. Porém, os velhos entusiastas anteciparam muito do que aconteceu nos últimos cinco anos. Era impossível que a cana não desse certo. Porém diversas preocupações surgem, principalmente com a sustentabilidade, que se divide no tripé economia, pessoas e planeta.

O que se observou no ano de 2007 não é sustentável em termos econômicos e de remuneração de pessoas e distribuição de renda. Diversos investimentos foram feitos em expansão da capacidade 
produtiva, confiando no crescimento do mercado interno e externo de álcool. Somado ao fato de o preço do açúcar estar extremamente baixo, praticamente os produtores de cana e usinas terminam o ano sem lucro nenhum, comprometendo o crescimento e a distribuição de renda, tão sonhadas para este setor. Fora isto, percebe-se que, para exportar o etanol, a cada dia é colocada uma nova dificuldade por nossos compradores potenciais. Muita bobagem é dita, inclusive com a injusta comparação do etanol de milho e outros grãos, com o etanol de cana.

A competitividade do Brasil na produção de etanol é ponto pacífico. Sua manutenção, contudo, depende da operacionalização de projetos estratégicos, da definição de responsáveis e da limitação de prazos e determinação de datas. Mais do que nunca, planejamento é necessário neste setor, para que todas as oportunidades possam ser alcançadas e seus pontos fracos combatidos, visando ao equilíbrio e à sustentabilidade. Assim, procurou-se, neste texto, debater mais idéias que levem aos "caminhos para a cana".

\section{REFERÊNCIAS BIBLIOGRÁFICAS}

ANFAVEA - Associação Nacional dos Fabricantes de Veículos. Disponível em: < http://www.anfavea. com.br/>.

ANP - Agência Nacional do Petróleo. Disponível em: < http://www.anp.gov.br/>.

BUAINAIN, A.M; BATALHA, M. O. (org.) Série Agronegócios: Cadeia Produtiva da Agroenergia, v. 3. Ministério da Agricultura Pecuária e Abastecimento - MAPA, 2006. 112 p.

CAMPOMAR, M.C.; IKEDA, A. A. Planejamento de Marketing: e a confecção de planos. São Paulo: Saraiva, 2006. 216 p.

CANADIAN RENEWABLE FUELS ASSOCIATION. Disponível em: <http://www.greenfuels. org/>.

CARD, Iowa University, EUA. Disponível em: < http://www.card.iastate.edu/>.

EIA/DOE - Energy Information Administration, Department of Energy, US. Disponível em: <http:// www.eia.doe.gov/ $>$.

FERREIRA, A. L. ; PRADO, F. P. A. ; SILVEIRA, J. J. The alcohol price and flex cars. In: INTERNATIONAL CONFERENCE ON POLICY MODELING. Ecomod, São Paulo, 2007.

F.O. LITCH'S. Disponível em: <http://www.agra-net.com/>.

FAO - UN Food and Agriculture Organization. Disponível em: < http://www.fao.org/>.

IBGE - Instituto Brasileiro de Geografia e Estatística. Disponível em: <http://www.ibge.gov.br/english/>.

ICONE - Institute for International Trade Negotiations - Brazil. Disponível em: <http://www.iconebrazil.org.br/en/>.

IEA - International Energy Agency. Disponível em: <http://www.iea.org/>.

IETHA - International Ethanol Trade Association. Disponível em: <http://www.ietha.org/ethanol/>.

IICA - Inter-American Institute for Cooperation on Agriculture. Disponível em: <http://www.iica.int/ Agroenergia/default.asp $>$.

JAIN, S. C. Marketing planning \& strategy, 6th ed. Cincinnati: Thomson Learning, 2000.

JOHNSON, G.; SCHOLES, K.. Exploring corporate strategy. 4th. ed. Prentice Hall, 1997. 866 p.

MAPA - Ministério da Agricultura do Brazil. Disponível em:<http://www.agricultura.gov.br/>.

MORAES, M. A. F. D; SHIKIDA, P. F. Agroindústria canavieira no Brasil: evolução, desenvolvimento e desafios. Editora Atlas, 2002. 367 p. 
NEVES, M. F. O novo posicionamento da velha cana. O Estado de São Paulo, 2004. Opinião Econômica, p. b2.

. A method for demand driven strategic planning and management for food chains (the chainplan method). In: 17th Annual World Forum and Symposium - Food Culture: Tradition, Innovation and Trust - A Positive Force for Modern Agribusiness, jun. 2007, Parma, Itália.

. Um modelo para o planejamento e gestão estratégica de marketing (orientação para o mercado) nas organizações. Tese (Livre Docência) - Departamento de Administração da Faculdade de Economia, Administração e Contabilidade de Ribeirão Preto da Universidade de São Paulo, 2004.

NIPE/UNICAMP - Núcleo Interdisciplinar de Planejamento Energético. Disponível em: < http://www. nipeunicamp.org.br/>.

OECD - Organization for Economic Cooperation and Development. Disponível em: $<$ http://www.oecd. org/>.

PURDUE UNIVERSITY, EUA. Disponível em:<http://www.ces.purdue.edu/bioenergy $>$.

RFA - Renewable Fuels Association. Disponível em: $<$ http://www.ethanolrfa.org/ $>$.

SCA Consultoria. Disponível em:<http://www.scaconsultoria.com.br/>.

UNICA - Associação das Indústrias de Cana de Açúcar, Brasil. Disponível em:<http://www.portalunica. com.br/portalunicaenglish/>.

USDA - US Department of Agriculture. Disponível em:<http://www.usda.gov/>.

WORLD BANK. Disponível em:<http://www.worldbank.org/>.

WWI - World Watch Institute. Disponível em:<http://www.worldwatch.org/>. 